NBER WORKING PAPERS SERIES

\title{
THE EQUITY PREMIUM AND THE RISK FREE RATE: MATCHING THE MOMENTS
}

\author{
Stephen G. Cecchetti \\ Pok-sang Lam \\ Nelson C. Clark
}

Working Paper No. 3752

\author{
NATIONAL BUREAU OF ECONOMIC RESEARCH \\ 1050 Massachusetts Avenue \\ Cambridge, MA 02138 \\ June 1991
}

Ohio State University and N.B.E.R; Ohio State University; and Ohio State University, respectively. We thank George Constantinides, Lawrence Christiano, Paul Evans, James Hamilton, N. Gregory Mankiw, Tony Smith, Robert Stambaugh, Alan Viard, Stanley $Z$ in and seminar participants at the 1989 NBER Sumer Institute, claremont, the Federal Reserve Bank of Minneapolis, the University of Illinois, Indiana University, Queens, Purdue, Vanderbilt, University of Virginia and the University of Washington for their comments and suggestions. Cecchetti acknowledges the financial support of the National Science Foundation. This paper is part of NBER's research program in Financial Markets and Monetary Economics. Any opinions expressed are those of the authors and not those of the National Bureau of Economic Research. 


\section{THE EQUITY PREMIUM AND THE RISK FREE RATE:} MATCHING THE MOMENTS

\section{ABSTRACT}

This paper investigates the ability of a representative agent model with time separable utility to explain the mean vector and the covariance matrix of the risk free interest rate and the return to leveraged equity in the stock market. The paper generalizes the standard calibration methodology by accounting for the uncertainty in both the sample moments to be explained and the estimated parameters to which the model is calibrated. We develop a testing framework to evaluate the model's ability to match the moments of the data.

We study two forms of the model, both of which treat leverage in a manner consistent with the data. In the first, dividends explicitly represent the flow that accrues to the owner of the equity, and they are discounted by the marginal rate of intertemporal substitution defined over consumption. The second form of the model introduces bonds and treats equities as the residual claim to the total endowment stream. We find that the first moments of the data can be matched for a wide range of preference parameter values. But for both models the implied first and second moments taken together are always statistically significantly different from the data at standard levels. This last result contrasts sharply with other recent treatments of leverage in the literature.

Stephen G. Cecchetti

Pok-sang Lam Nelson C. Mark Department of Economics Ohio State University Columbus, Ohio 43210-1172 


\section{Introduction}

A primary goal of financial economists is to understand the dynamics of asset price movements. Recent research has focused on measuring and explaining both the degree of serial correlation and the size and variation of asset returns. In an earlier paper, Cecchetti, Lam and Mark (1990), we study the first of these issues. ${ }^{1}$ Here, we examine the second. We show that a representative agent model based on Lucas (1978), calibrated either to historical consumption and dividend growth jointly, or to consumption alone but including bonds, can explain the first but not the second moments of the equity premium and the risk free rate found in the data.

The empirical issues that concern the work here were first discussed by Mehra and Prescott (1985). They show that for plausible values of the discount factor and the coefficient of relative risk aversion, a simple representative agent model that is calibrated to certain features of historical consumption data implies values of the equity premium that are 'too low' together with values of the risk free rate that are 'too high.' The difficulty that Mehra and Prescott found in using a frictionless, pure exchange Arrow-Debreu economy to match the first moments of the equity premium and the risk free rate is what has come to be known as the 'equity premium puzzle.'

This paper has two features that distinguish it from previous studies of equity returns. ${ }^{2}$ First, we explicitly model equities as a leveraged claim on the consumption process. It is common in the literature to set consumption and dividends equal, and then calibrate

\footnotetext{
${ }^{1}$ That paper shows how the negative serial correlation in asset returns found in sample is consistent with the equilibrium model described in Section 2 below.

${ }^{2}$ Numerous solutions have been proposed to this puzzle. A partial list includes Mankiw's (1986) suggestion that the high risk premium is the consequence of nondiversifiable risk; Reitz's (1988) examination of big crashes; Nason's (1988) study of the consequences of assuming that consumption has sorne lower bound; Abel's (1988) work on heterogeneous beliefs; Weil (1989) and Epstein and Zin's (1990) use of nonexpected utility; Constantinides's (1988) and Abel's (1990) models based on habit formation; Labadie's (1989) monetary model; and Mankiw and Zeldes' (1990) separation of stockholders from nonstockholders.
} 
the model to estimates of a univariate consumption process. But this practice ignores the fact that equities are actually levered claims to firms' production. Recently, both Kandel and Stambaugh (1990a, 1990b, 1991) and Benninga and Protopapadakis (1990) report success in matching the first and second moments of returns data using models with leverage. Those papers treat the leverage ratio - the ratio of debt to the market value of the firm - as a free parameter. These authors are implicitly allowing the share of dividends to consumption to vary in order to match the moments of returns. But the data provide a precise guide as to what this share should be. The payments to equity holders represent only a very small fraction of total consumption - during the twentieth century total dividends have averaged between $3 \%$ and $5 \%$ of aggregate consumption. When this ratio is imposed on the model, the model still cannot fully explain the data.

The second salient feature of this paper is that we develop a testing framework to measure the ability of the model to match the data. This addresses a common problem in the calibration literature. Previous authors generally fail to provide a well articulated criterion for evaluating the models they examine. To understand the problem, let $\psi_{T}$ be a vector of sample moments and $\mu(\theta ; \phi)$ be the corresponding implied moments from a completely specified economic model with parameter vectors $\theta$, representing technology, and $\phi$, representing tastes. Inspired first by Kydland and Prescott (1982) and then Mehra and Prescott (1985), recent asset pricing and business cycle research has explored various parameterizations in an attempt to set $\left[\psi_{T}-\mu(\theta ; \phi)\right]=0$. In this calibration method, the parameters of the technology, $\theta$, are estimated in order to conform to certain features of the actual economic environment. The investigator then searches over 'plausible' values of the preference parameters, $\phi$, in an attempt to find implied moments of the economic model that are 'close' to the sample moments. But this ignores two sources of uncertainty. Since $\psi_{T}$ is an estimator for the moments of interest, and $\theta$ is set equal to $\theta_{T}$, an estimator of the parameters of the technology, the compari- 
son can be thought of as testing to see if the difference between two jointly distributed random variables is zero.

By explicitly accounting for uncertainty that arises from the fact that $\psi_{T}$ and $\theta_{T}$ are estimated, we can calculate the distribution of $\left[\psi_{T}-\mu\left(\theta_{T}, \phi\right)\right]$, conditional on a particular choice of $\phi$, the taste parameters. This allows us to formulate a test statistic and apply standard inference procedures to evaluate the fit of the model. ${ }^{3}$

Our starting point is an equilibrium asset pricing model based on Lucas (1978), generalized to incorporate nontraded assets. We make assumptions about preferences and the stochastic process governing endowments that yield a closed form solution for asset prices. The utility function is time separable and in the constant relative risk aversion class, while the endowment obeys a form of Hamilton's (1989) Markov switching model.

We present two forms of the model. In the first, we assume that dividends represent the flow that accrues to the owner of the equity, and that these are discounted by the marginal rate of intertemporal substitution defined over consumption. This model mirrors the theory exactly in that equity prices are based solely on the flow that accrues to their owner.

The bivariate model requires that we estimate a stochastic process for consumption and dividend growth rates jointly. In the second model we pursue an alternative formulation in which we need only estimate the consumption process alone. Here we introduce single period bonds and price equity as the residual claim after the payments to the bonds have been made.

Both models are calibrated by setting the parameters of the endowment process equal to estimates of the Markov switching model

\footnotetext{
${ }^{3}$ In a recent paper, Hansen and Jagannathan (1990) suggest an alternative method for evaluating whether an asset pricing model is capable of matching the unconditional moments of the data. They examine the ability of various preference specifications to generate marginal rates of intertemporal substitution that match those implied by asset returns data. They find that time separable utility functions require substantial curvature to meet their criterion.
} 
using annual observations on U.S. real consumption and dividends from 1892 to 1987 . In the bond model, we restrict the leverage ratio to values that ensure that the share of the endowment to equity holders matches the average value in the data. We proceed to examine the ability of each model - the bivariate consumption-dividends model and the univariate consumption model with bonds - to explain the equity premium puzzle, i.e., the first moments of the equity premium and the risk free rate. As first suggested by Constantinides (1990), we also study the ability of the models to match the covariance matrix of the returns data. While leverage allows us to match the mean equity premium and risk free rate fairly easily, we find that our attempts to match the second moments requires a quantity of bonds that is inconsistent with the data.

The remainder of this paper is organized into six parts. Section 2 describes the asset pricing model and derives the closed form solution for asset prices for both the bivariate consumption-dividends model and the univariate model with bonds, assuming that endowment growth follows the Markov switching process. In section 3 we report estimates of the parameters of the processes constructed using Hansen's (1982) Generalized Method of Moments (GMM). Section 4 discusses the methodology for evaluating the performance of the models. Section 5 examines the ability of the bivariate consumptiondividends model to match the first moments of the equity premium and the risk free rate alone, as well as the first and second moments of the returns data together. In Section 6 we report results for the univariate consumption model with bonds. Section 7 contains concluding remarks.

\section{The Model}

This section presents the model of asset pricing we use and derives the solution for returns. We consider a variant of the $\mathrm{Lu}$ cas model in which a single nonstoreable consumption good is made 
available through an exogenous endowment process. ${ }^{4}$ Throughout, we assume that the endowment can be described by the Markov switching model first introduced by Hamilton (1989).

Two forms of the model are considered. They differ in their treatment of leverage. In the first version, we assume that the consumption good is generated by two distinct processes. Call the first process dividends, and let the claim to dividends be called equity. The price of equity is determined in a competitive market. The claim to the other endowment, which can be thought of as labor income, is not traded. Total consumption in any period is the sum of dividends and labor income. The economy is populated by a large number of identical individ uals who are aggregated into a representative agent. This model is presented in section 2.1. By contrast, in the second version of the model we assume that the equity is a residual claim on the endowment after one period real bonds have been paid off. This model is discussed in Section 2.4

\subsection{Bivariate Consumption-Dividends: The Investors}

We begin with the first order conditions for the generalized Lucas economy in which consumption and dividends are not necessarily equal. These are

$$
P_{t}^{e}=\beta E_{t}\left\{\frac{U^{\prime}\left(C_{t+1}\right)}{U^{\prime}\left(C_{t}\right)}\left[P_{t+1}^{e}+D_{t+1}\right]\right\}
$$

and

$$
P_{t}^{f}=\beta E_{t} \frac{U^{\prime}\left(C_{t+1}\right)}{U^{\prime}\left(C_{t}\right)}
$$

\footnotetext{
${ }^{4}$ The model presented here generalizes our earlier results presented in Cecchetti, Lam and Mark (1990). We follow the standard practice of the aggregate asset pricing literature and study an endowment economy. Since we are unconcerned with consumption decisions themselves, this makes little difference. In principle, we could specify a production economy and derive the stochastic process for technology that would be required to yield the consumption process we assume. All that is important for our work is that the consumption process fits the data.
} 
where

$P_{t}^{e}=$ the real price of the traded asset, or equity

$P_{t}^{f}=$ the real price of the risk free asset,

$C_{t}=$ per capita real consumption,

$D_{t}=$ the payoff or dividend from owning one unit of equity,

$U^{\prime}=$ the marginal utility of the representative agent,

$\beta=$ the discount factor, $0<\beta$, and

$E_{t}=$ the mathematical expectation conditional on information at time $t$.

Let preferences be given by,

$$
U\left(C_{t}\right)=\frac{C_{t}^{1-\gamma}}{1-\gamma}
$$

where $0<\gamma<\infty$ is the coefficient of relative risk aversion.

Now substitute (3) into (1) and (2) to obtain

$$
P_{t}^{e} C_{t}^{-\gamma}=\beta E_{t} C_{t+1}^{-\gamma}\left(P_{t+1}^{e}+D_{t+1}\right)
$$

and

$$
P_{t}^{f}=E_{t} \beta\left(\frac{C_{t+1}}{C_{t}}\right)^{-\gamma}
$$

We note here that in the empirical computations below $\beta$ is allowed to exceed unity. Kocherlakota (1990a) has shown that a unique solution to the asset pricing problem exists in economies where the discount factor is greater than one. ${ }^{5}$

\footnotetext{
${ }^{5}$ There are a number of ways to understand values of $\beta$ that are greater than one. For example, it can be thought of as a simple, but crude, way of approximating habit formation behavior of the type described in Constantinides (1990) and Abel (1990). In their models, marginal utility is an increasing function of the level of past consumption. This implies behavior similar to that implied by a discount factor greater than one.
} 


\subsection{Bivariate Consumption-Dividends: The Endowment}

We assume that consumption and dividends are governed by a bivariate version of Hamilton's (1989) Markov switching model. ${ }^{6}$ Our earlier paper [Cecchetti, Lam, and Mark (1990)] demonstrates the empirical usefulness of the Markov switching process for modeling consumption and dividend growth. In particular, we showed that this model is able to characterize the significant negative skewness and excess kurtosis that is found in the consumption and dividend growth data. Furthermore, the Markov switching model also admits a closed form solution to the asset pricing problem.

Let $c_{t} \equiv \ln C_{t}$ and $d_{t} \equiv \ln D_{t}$. We assume that $\left\{c_{t}, d_{t}\right\}$ is governed by the following bivariate random walk with two state Markov drift:

$$
\left(\begin{array}{c}
c_{t} \\
d_{t}
\end{array}\right)=\left(\begin{array}{c}
c_{t-1} \\
d_{t-1}
\end{array}\right)+\left(\begin{array}{c}
\alpha_{0}^{c} \\
\alpha_{0}^{d}
\end{array}\right)+\left(\begin{array}{c}
\alpha_{1}^{c} \\
\alpha_{1}^{d}
\end{array}\right) S_{t}+\left(\begin{array}{c}
\epsilon_{t}^{c} \\
\epsilon_{t}^{d}
\end{array}\right)
$$

where $\left(\begin{array}{c}\epsilon_{t}^{c} \\ \epsilon_{t}^{d}\end{array}\right)$ is i.i.d. normal with mean zero and covariance matrix $\Sigma=\left(\begin{array}{cc}\sigma_{c}^{2} & \sigma_{c d} \\ \sigma_{c d} & \sigma_{d}^{2}\end{array}\right)$, and $S_{t}$ is a Markov random variable which takes on values of 0 or 1 with transition probabilities

$$
\begin{aligned}
& \operatorname{Pr}\left[S_{t}=1 \mid S_{t-1}=1\right]=p \\
& \operatorname{Pr}\left[S_{t}=0 \mid S_{t-1}=1\right]=1-p \\
& \operatorname{Pr}\left[S_{t}=1 \mid S_{t-1}=0\right]=1-q \\
& \operatorname{Pr}\left[S_{t}=0 \mid S_{t-1}=0\right]=q .
\end{aligned}
$$

The model requires estimation of nine parameters: $\left(\alpha_{0}^{c}, \alpha_{0}^{d}, \alpha_{1}^{c}, \alpha_{1}^{d}\right.$, $\left.p, q, \sigma_{c}^{2}, \sigma_{d}^{2}, \sigma_{c d}\right) .^{7}$

\footnotetext{
${ }^{6}$ We model consumption, rather than labor income, jointly with dividends to maintain tractability of the model. We note that this formulation places implicit restrictions on the production technology that we do not investigate. See footnote 4 above.

${ }^{7}$ Because consumption is nearly 20 times the size of dividends in the data, the
} 
As a normalization, we restrict the $\alpha_{1}$ 's to be negative. Consequently the economy will be in a good state when $S_{t}=0$, and in a bad state when $S_{t}=1$. The parameter $q$ is the probability of remaining in the good state next period given that the economy is currently in the good state, while $p$ is the probability of remaining in the bad state given that the economy is currently in the bad state. The transition probabilities between the two states are $(1-q)$ and $(1-p)$.

The Markov components of the dividend and consumption processes are assumed to be perfectly correlated, and so dividends and consumption are in the good or the bad state simultaneously. The mean consumption and dividend growth rates are $\alpha_{0}^{c}$ and $\alpha_{0}^{d}$ in the good state, and $\left(\alpha_{0}^{c}+\alpha_{1}^{c}\right)$ and $\left(\alpha_{0}^{d}+\alpha_{1}^{d}\right)$ in the bad state.

The bivariate Markov switching model generalizes the Markov growth process of Mehra and Prescott in three ways. First, consumption and dividends are modeled jointly. Second, the continuous random variable $\epsilon$ is included. Third, the transition matrix in (7) is permitted to be asymmetrical. We obtain the Mehra and Prescott endowment process by setting $C=D, p=q$ and $\Sigma=\underline{0}$.

\subsection{Bivariate Consumption-Dividends: The Solution}

Assuming that consumption and dividends follow the bivariate process given by (6) and (7), we obtain the closed form solution for the price of a share of equity and the price of the risk free asset by the method of undetermined coefficients. ${ }^{8}$ Conjecture the following solution:

$$
P_{t}^{e}=\rho\left(S_{t}\right) D_{t}
$$

probability that the model will ever imply a negative value for nonlabor income $\left(C_{t}-D_{t}\right)$ is vanishingly small, even though $\sigma_{d}^{2}$ is nearly 10 times $\sigma_{c}^{2}$. See Table 1 for details.

${ }^{8}$ The technique presented here can also be used to obtain a solution for the general case in which the endowment follows an $n$-state Markov switching process in the mean, the variance, or both. 
The problem is to verify that (8) solves (4), and to find the function $\rho\left(S_{t}\right)$. To do this, first substitute (8) into (4) to obtain:

$$
\rho\left(S_{t}\right) D_{t} C_{t}^{-\gamma}=\beta E_{t} C_{t+1}^{-\gamma} D_{t+1}\left[\rho\left(S_{t+1}\right)+1\right]
$$

Next, write (6) in levels,

$$
\left[\begin{array}{c}
C_{t+1} \\
D_{t+1}
\end{array}\right]=\left[\begin{array}{c}
C_{t} e^{\left(\alpha_{0}^{c}+\alpha_{1}^{c} S_{t+1}+\epsilon_{t+1}^{c}\right)} \\
D_{t} e^{\left(\alpha_{0}^{d}+\alpha_{1}^{d} S_{t+1}+\epsilon_{t+1}^{d}\right)}
\end{array}\right]
$$

Now substitute (10) into (9) and note that $\epsilon_{t}^{c}$ and $\epsilon_{t}^{d}$ are i.j.d. normal with covariance matrix $\Sigma$ to obtain

$$
\rho\left(S_{t}\right)=\beta e^{\left[\alpha_{0}^{d}-\gamma \alpha_{0}^{c}+\frac{1}{2}\left(\gamma^{2} \sigma_{c}^{2}-2 \gamma \sigma_{c d}+\sigma_{d}^{2}\right)\right]} E_{t} e^{\left(\alpha_{1}^{d}-\gamma \alpha_{1}^{c}\right) S_{t+1}}\left[\rho\left(S_{t+1}\right)+1\right]
$$

Because $S_{t}$ can take on only two values, 0 or $1,(11)$ is a system of two linear equations in $\rho(0)$ and $\rho(1)$. Solving these two equations yields

$$
\rho(0)=\frac{1-(p+q-1) \tilde{\alpha}_{1} \tilde{\beta}}{1-\tilde{\beta}\left(p \tilde{\alpha}_{1}+q\right)+\tilde{\beta}^{2} \tilde{\alpha}_{1}(p+q-1)}-1
$$

and

$$
\rho(1)=\frac{1-(p+q-1) \tilde{\beta}}{1-\tilde{\beta}\left(p \tilde{\alpha}_{1}+q\right)+\tilde{\beta}^{2} \tilde{\alpha}_{1}(p+q-1)}-1 .
$$

where

$$
\begin{aligned}
\tilde{\beta} & =\beta e^{\left[\alpha_{0}^{d}-\gamma \alpha_{0}^{c}+\frac{1}{2}\left(\gamma^{2} \sigma_{c}^{2}-2 \gamma \sigma_{c d}+\sigma_{d}^{2}\right)\right]}, \\
\text { and } \quad \tilde{\alpha}_{1} & =e^{\alpha_{1}^{d}-\gamma \alpha_{1}^{c}} .
\end{aligned}
$$

This establishes that (8) is the solution to (4). ${ }^{9}$

\footnotetext{
${ }^{9}$ The solution for the equity price can also be obtained by iterating the stoch astic difference equation (8) forward and exploiting results in Hamilton (1989) to evaluate the resulting geometric series. The conditions required for this series to converge also guarantee that $\rho\left(S_{t}\right)$ is nonnegative. The nonnegativity of $\rho\left(S_{t}\right)$ is always imposed in the empirical work that follows.
} 
The price of the risk free asset is obtained using (6) and (7) to evaluate (5). That is,

$$
P_{t}^{f}=\beta e^{\left(-\gamma \alpha_{0}^{c}+\frac{1}{2} \gamma^{2} \sigma_{c}^{2}\right)} \varphi\left(S_{t}\right),
$$

where $\varphi(0)=q+(1-q) e^{-\gamma \alpha_{1}^{c}}$, and $\varphi(1)=p e^{-\gamma \alpha_{1}^{c}}+(1-p)$. The implied rates of return to holding the equity and risk free assets from date $t$ to $t+1$ are,

$$
\begin{aligned}
R_{t}^{e}=R^{e}\left(S_{t+1}, S_{t}, \epsilon_{t+1}^{d}\right) & =\frac{P_{t+1}+D_{t+1}}{P_{t}}-1 \\
& =\frac{\rho\left(S_{t+1}\right)+1}{\rho\left(S_{t}\right)} e^{\left(\alpha_{0}^{d}+\epsilon_{t+1}^{d}+\alpha_{1}^{d} S_{t+1}\right)}-1 .
\end{aligned}
$$

and

$$
R_{t}^{f}=R^{f}\left(S_{t}\right)=\frac{1}{P^{f}\left(S_{t}\right)}-1 .
$$

Next, integrate $\epsilon_{t+1}^{d}$ out of the expression for the equity return to obtain

$$
R^{e}\left(S_{t+1}, S_{t}\right)=\frac{\rho\left(S_{t+1}\right)+1}{\rho\left(S_{t}\right)} e^{\left(\alpha_{0}^{d}+\frac{1}{2} \sigma_{d}^{2}+\alpha_{1}^{d} S_{t+1}\right)}-1 .
$$

Finally, the implied means of the risky and the risk free rates of return are computed by summing over the probabilities:

$$
\begin{aligned}
\mu^{e}=E\left[R^{e}\left(S_{t+1}, S_{t}\right)\right]= \\
\sum_{s_{t+1}=0}^{1} \sum_{s_{t}=0}^{1} \operatorname{Pr}\left(S_{t+1}=s_{t+1} \mid S_{t}=s_{t}\right) \operatorname{Pr}\left(S_{t}=s_{t}\right) R^{e}\left(s_{t+1}, s_{t}\right),
\end{aligned}
$$

and

$$
\mu^{f}=E\left[R^{f}\left(S_{t}\right)\right]=\sum_{s_{t}=0}^{1} \operatorname{Pr}\left(S_{t}=s_{t}\right) R^{f}\left(s_{t}\right) .
$$

The expected equity premium follows as

$$
\mu^{p}=\mu^{e}-\mu^{f} .
$$


The implied covariance matrix for the premium and the risk free rate is:

$$
\begin{gathered}
\operatorname{Var}\left(\begin{array}{c}
R_{t}^{p} \\
R_{t}^{f}
\end{array}\right)=\sum_{s_{t+1}=0}^{1} \sum_{s_{t}=0}^{1} \operatorname{Pr}\left(S_{t+1}=s_{t+1} \mid S_{t}=s_{t}\right) \operatorname{Pr}\left(S_{t}=s_{t}\right) \mathrm{x} \\
\quad\left[\begin{array}{c}
R_{t}^{p}-\mu^{p} \\
R_{t}^{f}-\mu^{f}
\end{array}\right]\left[\begin{array}{l}
R_{t}^{p}-\mu^{p} \\
R_{t}^{f}-\mu^{f}
\end{array}\right]^{\prime}
\end{gathered}
$$

\subsection{Univariate Consumption with Bonds}

An alternative to the bivariate consumption-dividends model above is to ignore dividends and examine the role of bonds instead. To study the implications of this for equity returns, we introduce a leverage parameter that determines the quantity of bonds outstanding. These bonds are the primary claim on the consumption flow, while equity holders have the residual claim. Put another way, we explicitly model the total endowment flow as accruing to the holders of two assets: bonds and equity shares.

The Modigliani-Miller theorem holds in this economy - the value of the firm is unaffected by the presence of the bonds. But while the existence of the bonds does not change the price and return of the sum of bonds and equity, it does change the value of the two pieces. The riskiness of equity is increased by the issuance of bonds because the return to the bonds must be guaranteed in advance.

To derive the return to equity, we first use the results of Section 2.3 to calculate the total market value of the firm, i.e. debt plus equity. Next, we introduce single period bonds and derive their price in the presence of costless bankruptcy risk. This enables us to compute the price and return to holding the equity as the residual claim on the income of the firm.

To see how this all works, start by defining $P_{t}^{m}$ to be the beginning of period value of the firm. Each period $B_{t}$ bonds are issued. At $t+1$ the bonds pay off either one unit of the consumption good, 
or $\frac{\left(P_{t+1}^{m}+C_{t+1}\right)}{B_{t}}$, whichever is smaller. If $\left(P_{t+1}^{m}+C_{t+1}\right)$ is greater than $B_{t}$, then the holder of the equity shares receive a distribution equal to $\left(P_{t+1}^{m}+C_{t+1}-B_{t}\right)$. If $B_{t}$ is greater than $\left(P_{t+1}^{m}+C_{t+1}\right)$, then there is costless bankruptcy in which the entire value of the firm is transferred to the bondholders. In other words, solvency requires that the liquidation value of the firm be sufficient to pay off the outstanding debt. ${ }^{10}$

Next, using the results of Section 2.3 we compute the value of the firm $P_{t}^{m}$. Since the entire endowment stream accrues to the owner of the firm, we can compute $P_{t}^{m}$ from the first order condition (1) by setting the dividend $D_{t}$ equal to consumption $C_{t}$. The solution is

$$
P_{t}^{m}\left(S_{t}\right)=\rho_{\ell}\left(S_{t}\right) C_{t},
$$

where $\rho_{\ell}\left(S_{t}\right)$ is defined by (12) and (13), the definition of $\rho\left(S_{t}\right)$, after setting dividends equal to consumption. In other words, to obtain $\rho_{\ell}\left(S_{t}\right)$, replace $\alpha_{0}^{d}$ with $\alpha_{0}^{c}, \alpha_{1}^{d}$ with $\alpha_{1}^{c}, \sigma_{d}$ with $\sigma_{c}$, and $\sigma_{c d}$ with $\sigma_{c}^{2}$ in the expressions defining $\rho\left(S_{t}\right)$.

The next step in computing the effect of bonds on the return to holding equity, is to calculate the price and return to holding a bond. In the context of this model, bonds represent all of the claims to the endowment not accounted for by equity. ${ }^{11}$ We assume that the debt issue in period $t$ is a constant multiple of the date $t$ level of consumption,

$$
B_{t}=e^{-\omega} C_{t}
$$

${ }^{10} \mathrm{Kandel}$ and Stambaugh $(1990 \mathrm{a}, 1990 \mathrm{~b}, 1991)$ treat leverage in a way analogous to ours. Benninga and Protopapadakis (1990) also consider the impact of the existence of bonds on the equity premium. In their model, bonds pay the risk free rate and their is no possibility of bankruptcy. This formulation would be incorrect in our context since the probability of bankruptcy is never zero when the endowment follows the Markov switching process.

${ }^{11}$ In their original paper, Mehra and Prescott (1985) note that equity is the residual claim to output after labor has been paid, but in contrast to Benninga and Protopapadakis (1990), they find that it does not help in generating a large equity premium. Brainard and Summers (1990), who also examine the impact of bonds, claim that the Mehra and Prescott analysis is misleading. 


\section{Conclusion}

This paper addresses two issues central to the literature in calibration and aggregate asset pricing. First, we develop a testing framework for rigorously evaluating the ability of an economic model to match specific sample moments of the historical data. Second, we reexamine the ability of leverage to solve the equity premium puzzle.

Using a methodology that combines the features of model calibration and classical statistical inference, we conclude that a simple general equilibrium model is capable of matching the first moments of asset returns alone, but not the first and second moments together. ${ }^{30}$ This suggests that previous authors who examine the implications of leverage for matching the moments of aggregate asset returns have allowed themselves too much leeway to do so. In general, the amount of leverage required to rehabilitate the intertemporal consumption based asset pricing model with time separable utility is far below what we see in the real world.

We conclude that modeling leverage is not sufficient to salvage the Lucas asset pricing model with time separable utility. The original Mehra-Prescott form of the equity premium puzzle, based solely on first moments, does not seem to present a challenge for the model. But when the endowment is forced to conform closely to the data, as it is in the Markov switching model, and leverage is forced to imply that the dividend flow match what we actually observe, then the model can not match the five first and second moments taken together.

\footnotetext{
${ }^{30}$ As we demonstrate in our earlier paper, Cecchetti, Lam and Mark (1990), this model is capable of matching the serial correlation in equity returns.
} 


\section{Appendix}

Here we describe the procedure we use to obtain the GMM estimator of the parameters of the endowment process, $\theta_{T}$, the sample moments, $\psi_{T}$, and the estimate of their asymptotic covariance matrix.

Let $\left\{x_{t}\right\}$ be a vector valued sequence of observations on stock and bond returns, and consumption and dividend growth rates. Let $\lambda^{\prime}=\left(\psi^{\prime}, \theta^{\prime}\right)$ denote the parameter whose true value is $\lambda_{o}^{\prime}=\left(\psi_{o}^{\prime}, \theta_{o}^{\prime}\right)$. Finally, let $f\left(x_{t}, \lambda\right)$ be the vector of moment conditions used in the estimation of $E f\left(x_{t}, \lambda_{o}\right)=0$. To construct $f\left(x_{t}, \lambda\right)$, we stack moment conditions used to compute the sample moments of returns with those for estimating the endowment process parameters. That is,

$$
f\left(x_{t}, \lambda\right)=\left[\begin{array}{c}
f_{1}\left(x_{t}, \psi\right) \\
f_{2}\left(x_{t}, \theta\right)
\end{array}\right]
$$

When both the first and second moments of returns are required,

$$
f_{1}\left(x_{t}, \psi\right)=\left[\begin{array}{c}
r_{p, t}-\psi^{p} \\
r_{f, t}-\psi^{f} \\
\left(r_{p, t}-\psi^{p}\right)^{2}-\sigma_{p}^{2} \\
\left(r_{f, t}-\psi^{f}\right)^{2}-\sigma_{f}^{2} \\
\frac{\left(r_{p, t}-\psi^{p}\right)\left(r_{f, t}-\psi^{f}\right)}{\sigma_{p} \sigma_{f}}-\rho_{p f}
\end{array}\right]
$$

where $r_{p, t}$ and $r_{f, t}$ are the observations in the data at time $t$ for the risk premium and the risk free rate. When we require only the first moments of returns, we use only the first two elements of (A2).

$f_{2}\left(x_{t}, \theta\right)$ is a vector of deviations of the population moments from their sample counterparts implied by either Hamilton's Markov switching model, the Mehra-Prescott style Markov model, or the geometric random walk model. Let $x_{c, t}$ and $x_{d, t}$ denote the consumption and dividend growth rate at date $t$. For the bivariate consumptiondividends model we use the following moments: 
Markov switching model -10 moments:

$$
\begin{aligned}
E\left(x_{k, t}^{j}\right) & j=1,2,3 ; k=c, d . \\
E\left(x_{d, t}^{2} x_{d, t-1}\right) & \\
E\left(x_{c, t}^{j} x_{d, t}^{j}\right) & j=1,2 . \\
E\left(x_{c, t} x_{d, t-1}\right) &
\end{aligned}
$$

Mehra-Prescott style model -5 moments:

$$
\begin{array}{r}
E\left(x_{k, t}^{j}\right) \\
E\left(x_{c, t} x_{c, t-1}\right)
\end{array} \quad j=1,2 ; k=c, d .
$$

Random Walk model -5 moments:

$$
\begin{array}{r}
E\left(x_{k, t}^{j}\right) \\
E\left(x_{c, t} x_{d, t}\right)
\end{array} \quad j=1,2 ; k=c, d .
$$

To evaluate the bond model, we need to estimate only parameters of the consumption process. For this, we use the following moments:

Markov switching model -7 moments:

$$
\begin{aligned}
E\left(x_{c, t}^{j}\right) & j=1,2,3,4 . \\
E\left(x_{c, t}^{j} x_{c, t-1}^{j}\right) & j=1,2 . \\
E\left(x_{c, t}^{2} x_{c, t-1}\right) &
\end{aligned}
$$

Mehra-Prescott style model -3 moments:

$$
\begin{array}{r}
E\left(x_{c, t}^{j}\right) \\
E\left(x_{c, t} x_{c, t-1}\right)
\end{array} \quad j=1,2 .
$$


In order to construct the GMM estimator, let

$$
\begin{aligned}
g_{T} & =\frac{1}{T} \sum_{t=1}^{T} f\left(x_{t}, \lambda\right) \\
W_{T, 0} & =\frac{1}{T} \sum_{t=1}^{T} f\left(x_{t}, \lambda\right) f\left(x_{t}, \lambda\right)^{\prime}, \\
W_{T, j} & =\frac{1}{T} \sum_{t=1}^{T} f\left(x_{t}, \lambda\right) f\left(x_{t+j}, \lambda\right)^{\prime}, \\
w_{j, m} & =1-\frac{j}{m+1}, \\
W_{T} & =W_{T, 0}+\sum_{j=1}^{m} w_{j, m}\left[W_{T, j}+W_{T, j}^{\prime}\right], \\
D_{T} & =\frac{1}{T} \sum_{t=1}^{T} \frac{\partial f\left(x_{t}, \lambda\right)}{\partial \lambda} .
\end{aligned}
$$

The GMM estimator, $\lambda_{T}$, minimizes the quadratic criterion function

$$
\Phi(\lambda)=g_{T}^{\prime} W_{T} g_{T}
$$

and the asymptotic covariance matrix of $\lambda_{T}$ is consistently estimated by

$$
\frac{1}{T}\left[D_{T}^{\prime} W_{T}^{-1} D_{T}\right]^{-1}
$$

where $W_{T}$ is the Newey and West (1987) estimator of the spectral density matrix of $f\left(x_{t}, \lambda\right)$ at frequency zero. We set $m=3$, which conforms to Newey and West's $T^{\frac{1}{4}}$ rule. We obtain estimates of the covariance matrices $\Omega_{\theta}, \Omega_{\psi}$ and $\Omega_{\psi \theta}$ from the relevant blocks of (A4).

While the selection of any particular set of moment conditions for estimation using the GMM procedure is necessarily arbitrary, it is immaterial asymptotically under the null that the model is correctly specified. But in any finite sample, different estimates will emerge when different moment conditions are used.

The moment conditions that we used to obtain the Markov switch- 
ing model estimates reported in the text were chosen using two criteria. First, that the number of moments conditions should be relatively small, and second, that the estimates lie close to the maximum likelihood estimates.

It is not possible to use a Hausman test to assess whether the GMM estimates lie close to the maximum likelihood estimates, since both estimators may be inconsistent under the alternative. We can do a Wald test by assuming that one set of estimates is a vector of constants. Let $\theta_{m l}$ and $\Sigma_{\theta, m l}$ be the maximum likelihood estimator of the endowment process parameter vector, and its asymptotic covariance matrix. Suppose we view $\theta_{T}$ as a vector of constants and construct a Wald test for the hypothesis that $\theta_{m l}=\theta_{T}$. That is, we compute the Wald statistics $T\left(\theta_{m l}-\theta_{T}\right)^{\prime} \Sigma_{\theta, m l}^{-1}\left(\theta_{m l}-\theta_{T}\right)$. Setting $\theta_{T}$ to the estimates obtained from the GMM procedure, the Wald statistic are 14.91 (p-value 0.09 ) for the bivariate consumption-dividends model, and 1.69 (p-value 0.89 ) for the univariate consumption process.

Alternatively, we can use the estimate of the asymptotic covariance matrix of the GMM estimator to compute the Wald statistic and view $\theta_{m l}$ as a vector of constants. In this case, the Wald statistic are 16.92 ( $\mathrm{p}$-value 0.05 ) for the bivariate consumption-dividends model, and 3.22 ( $\mathrm{p}$-value 0.66 ) for the univariate consumption process.

Finally, we mention that Hansen's test of the overidentifying restrictions does not indicate much evidence against the Markov switching model. His J-statistic, $\left[J=T \Phi\left(\lambda_{T}\right)\right]$, is 0.007 (p-value 0.93 ) for the bivariate consumption-dividends model, and 2.185 (pvalue 0.34 ) for the univariate consumption model. 


\section{REFERENCES}

Abel, Andrew B., 'Asset Prices under Heterogeneous Beliefs: Implications for the Equity Premium Puzzle,' mimeo., Department of Finance, Wharton School, University of Pennsylvania, January 1988.

'Asset Prices under Habit Formation and Catching Up with the Joneses,' American Economic Review 80 (May 1990) 38-42.

Balke, Nathan S. and Robert J. Gordon, "Appendix B. Historical Data," in R. J. Gordon, Ed., The American Business Cycle. Chicago, Ill.: University of Chicago Press (for NBER), 1986.

Benninga, Simon and Aris Protopapadakis, 'Time Preference and the "Equity Premium Puzzle", Journal of Monetary Economics 25 (January 1990) 49-58.

Brainard, William C. and Lawrence H. Summers, 'Leverage and the Equity Premium Puzzle,' mimeo., Department of Economics, Yale University, May 1990.

Burnside ,A. Craig, "The Comovement of Asset Returns with Time Non-Separable Preferences," Department of Economics Queens University, August, 1990.

Campbell, John Y. and Robert J. Shiller, 'Cointegration and Tests of the Present Value Model,' Journal of Political Economy 95 (October 1987) 1062-1088.

Cecchetti, Stephen G., Pok-sang Lam and Nelson C. Mark, 'Mean Reversion in Equilibrium Asset Prices,' American Economic Review 80 (June 1990), 398-418.

Constantinides, George M., 'Habit Formation: A Resolution of the Equity Premium Puzzle,' mimeo., Graduate School of Business, University of Chicago, October 1988, and Journal of Political Economy 98 (June 1990) 519-543.

Epstein, Larry G. and Stanley E. Zin, "First-Order" Risk Aversion and the Equity Premium Puzzle,' Journal of Monetary Economics 26 (December 1990) 387-407. 
Gregory, Allan W. and Gregor W. Smith, 'Calibration as Testing: Type I Error in the Equity Premium Puzzle,' mimeo., Department of Economics, Queen's University, August 1988.

Grossman, Sanford J. and Robert J. Shiller, 'Consumption Correlatedness and Risk Measurement in Economies with Non-Traded Assets and Heterogeneous Information,' Journal of Financial Economics 10 (July 1982) 195-210.

and 'The Determinants of the Variability of Stock Market Prices,' American Economic Review 71 (May 1981), 222227.

Hamilton, James D., 'A New Approach to the Economic Analysis of Nonstationary Time Series and the Business Cycle,' Econometrica 57 (March 1989) 357-384.

Hansen, Lars Peter, 'Large Sample Properties of Generalized Method of Moments Estimators,' Econometrica 50 (November 1982) 10291054.

and Ravi Jagannathan, 'Implications of Security Market Data for Models of Dynamic Economies,' Journal of Political Economy 99 (April 1991) 225-262.

Kandel, Shmuel and Robert F. Stambaugh, 'Modeling Expected Stock Returns for Long and Short Horizons,' mimeo, Department of Finance, Wharton School, University of Pennsylvania, 1990. (a and , 'Expectations and the Volatility of Consumption and Asset Returns,' The Review of Financial Studies 3 (1990) 207232.

and 'Asset Returns and Intertemporal Preferences,' Journal of Monetary Economics 27 (February 1991) 39-72.

Kocherlakota, Narayana R., 'A Note on the "Discount" Factor in Growth Economies,' Journal of Monetary Economics 25 (January 1990) 43-48. (a)

, 'On Tests of Representative Consumer Asset Pricing Models,' Journal of Monetary Economics 26 (October 1990) 285-304 (b) 
Kuznets, Simon. National Income and Its Composition. Volume 1, New York: National Bureau of Economic Research, 1941.

Lee, Bong-Soo and Beth Fisher Ingram, 'Simulation Estimation of Times-Series Models,' Journal of Econometrics 47 (February/March 1991) 197-206.

Kydland, Finn and Edward C. Prescott, 'Time to Build and Aggregate Fluctuations,' Econometrica 50 (November 1982): 13451370.

Labadie, Pamela A., 'The Effects of Stochastic Inflation on Asset Prices,' Journal of Monetary Economics 24 (September 1989): 277-298.

Lucas, Robert E. Jr., 'Asset Prices in an Exchange Economy,' Econometrica 66 (1978) 1429-1445.

Mankiw, N. Gregory, 'The Equity Premium and the Concentration of Aggregate Shocks,' Journal of Financial Economics 17 (1986) 211-219.

and Stephen P. Zeldes, 'The Consumption of Stockholders and Non-Stockholders,' Harvard Institute of Economic Research Discussion Paper No. 1533, December 1990, Journal of Financial Economics, forthcoming.

Mehra, Rajnish and Edward C. Prescott, 'The Equity Premium: A Puzzle,' Journal of Monetary Economics 15 (March 1985) 145161.

Nason, James N., 'The Equity Premium and Time-Varying Risk Behavior,' Board of Governors of the Federal Reserve, Finance and Economics Discussion Paper No. 11, February 1988.

Newey, Whitney K. and Kenneth D. West, 'A Simple, Positive Definite, Heteroskedasticity and Autocorrelation Consistent Covariance Matrix,' Econometrica 55, May 1987, 703-708.

Reitz, Thomas A., 'The Equity Premium: A Solution,' Journal of Monetary Economics 22 (July 1988) 117-133.

Weil, Phillipe, 'The Equity Premium Puzzle and the Riskfree Rate Puzzle,' Journal of Monetary Economics 24 (November 1989) 401422. 
Wilson, Jack W. and Charles Jones, 'Inflation Measure for the Period,' mimeo., Department of Economics and Business, North Carolina State University, September 1988. 